\title{
Review HR Perspective toward the Role of Multinational Corporations (MNCs) in Thailand
}

\author{
Author \\ Sineenat Suasungnern, Nico Irawan, Atchara Salee, Ada Marie Gallego Mascarinas \\ Correspondence \\ International College of Rajamangala University of Technology Krungthep, Thailand
}

doi : 10.30587/kontribusia.v1i1.249

URL:http://dx.doi.org/10.30587/kontribusia.v1i1.249

\begin{abstract}
The study is using a qualitative strategy to describe the HR perspective towards the Role of Multinational Corporations (MNCs) in Thailand by using the pervious instrumental study review. Then, the data was classified into three parts: Part I: MNCs in developing countries; Part II: Overview the context of Thailand; Part III: Review the Role of MNCs in Thailand from the HR Perspective. As Thailand is a developing country which takes into account of globalization activities, hence, MNCs play an important role to enhance the level of economic growth. The developing countries must improve their infrastructure and skilled workers to be reach the competitive advantage among region and attractive to foreign direct investments. The result of the study showed the characteristics in social context in Thailand, how the beliefs of Thai society impact ethical behavior, attitude in business and implications of HR practices. Thai political context is identified the situation of replacement employees. The study describe that the qualification require has go to foreigners rather than Thai workers. Thai labor laws has identified the inequality of Social Security Circumstances between private sector, agricultural workers, and public employees. and the role of MNCs in Thailand from the HR perspective. It shows that HRD systems must be able to enhance and build a quality program to put people to work.
\end{abstract}

Keywords: Human Resources Perspective, Multinational Corporations (MNCs), Thailand

\section{Introduction}

The world has seen a tremendous increase in the quantity of global transactions and foreign trade in recent years. The main reason behind this is that now more countries are engaged in trading with each other in order to increase their profit or sales or to protect their markets from being eroded by competition. The main objectives influencing the companies to engage in international business are expansion of sales, acquiring resources, minimizing competitive risk and diversification of sources of sales and supplies (Johnson \& Turner,
Received: 15 December 2017. Accepted: 15 January 2018 2003).

A current trend in business sees large companies move across their home countries borders to conduct business in foreign markets. Competitively, global firms are constantly growing into new markets that show great potential for success. However, these newly entered conglomerates pose an additional threat to local existing businesses and culture. MNCs entering into new markets can have both positive and negative impacts on local economics; therefore, a greater understanding of corporate globalization 
must be achieved by global firms and those in the field of business.

In the New Economy, the business environment has rapidly changed and become increasingly complex. The New Economy refers to the present round of global growth, emerging businesses, new technology, intellectual capital, continuous change, continuing competition and sustainable development. These changes require companies to focus on various aspects, such as cooperation, values and culture, organizational capabilities, leadership development, attracting/retaining talent, strategic recruiting, change management, and diversity management.

In recent years accelerating globalization has raised significant implications for the regulation and governance of international business, trade and investment. Globalization implies no fundamental shift in the underlying principles of trading or business functions but simply more cross-border transactions. In simpler terms it includes all commercial transactions - private and governmental - between two or more countries. Private companies undertake such transactions for profit; governments may or may not do the same in their transactions (Fatima, 2007).

The emergence and activities of multinational enterprises have impacted to a huge extent on the concept of globalization. Given the MNCs international reach and mobility, prospective countries, and sometimes regions within countries, must compete with each other to have MNCs locate their facilities (and subsequent tax revenue, employment and economic activity) within (Fatima, 2007).

To compete, countries and regional political districts offer incentives to MNCs such as tax breaks, pledges of governmental assistance or improved infrastructure, or lax environmental and labor standards. This process of becoming more attractive to foreign investment can be characterized as a race to the bottom. Thus, we see MNCs hold strong positions in different channels of globalization: they account for all foreign direct investment (FDI), they are very active in trade, with one third of world trade taking place within and not between companies, and they transfer the bulk of technology and knowledge across borders via intra-firm transactions (Fatima, 2007).

\section{The Purpose of this Article}

As globalization of the economy and the increasing role of MNCs and fast business networks- including financial market linkages also raise fears about issues of stabilization, inequality and inefficiency. This article is a review article that focuses on the role of multinational corporations (MNCs) in Thailand. It provides into three parts: (1) MNCs in developing countries, (2) Overview the Context of Thailand, and (3) Review the role of MNCs in Thailand from the HR perspective

\section{Part I: MNCs in developing countries}

Developing countries have the following characteristics: their economies grew extensively over the past two decades, e.g., China, India, and Thailand.

Studies have been undertaken in order to evaluate the effects of MNCs on developing countries (Abdul-Gafaru, 2007; Meyer, 2004). In the last two decades, globalization has contributed to significant increases in foreign investment in developing countries, and thus bringing some of them more political and structural stability. In addition, it is commonly admitted that MNC's play a role in creating new kind of jobs and therefore can contribute to economic growth and the 
increase of welfare. As well, 1the infiltration of MNCs to developing countries has a potential to augment the salary level of employed people, hence increasing the buying power of the local citizens, which in turn will lead to increased tax payments. The availability of more resources will allow the government to spend more money in social welfare areas such as education, health care, and infrastructure building.

The investments by foreign companies make the developing countries more receptive to social and economic changes as they enter in the global market and they have to adopt modern values and business practices. The host country should facilitate the operations of MNCs because their direct investments are much easier to obtain than funding from traditional channels such as the World Bank, national development organizations, or non-profit organizations.

There is a growing recognition that MNCs could potentially impact several dimensions that are crucial for developing countries aiming at improving their competitiveness. These dimensions include capital, competences/skills, exports, technology/processes and infrastructure, as shown in Figure 1.

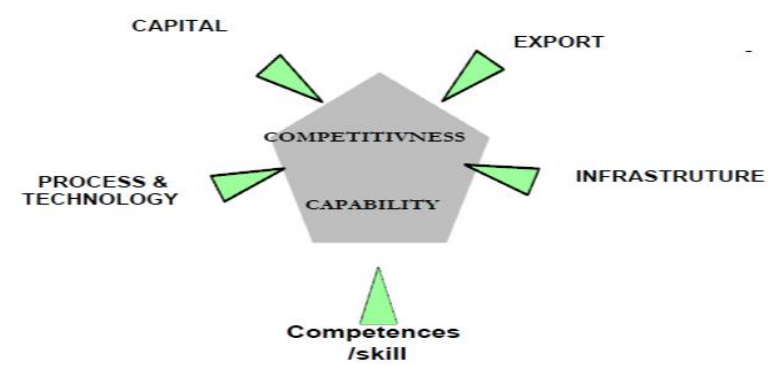

Figure 1 Five dimensions of competitiveness

(Worasinchai \& Bechina, 2010, pp. 171-180)

Capital represents an essential economic asset in developing countries. Foreign Direct
Investment (FDI) provided by MNCs contributes to a large extent to the flow of needed resources.

Infrastructure is a key element to attract potential foreign investors. A poor infrastructure presents many impediments to progress. The host countries are often engaged in improving their infrastructure in terms of road building, telecommunication, easier access to some parts of the country (Worasinchai \& Bechina, 2010).

Building Export capacity is very important for developing countries if they want to benefit fully from international trade and investment opportunities. Therefore, the government must seek to develop a regulatory framework that could assist local and regional areas in designing and implementing active policies for building export competitiveness. For example, many foreign companies in Thailand are offered tax and financial incentives to establish in a free trade zone, in order to facilitate exports (Worasinchai \& Bechina, 2010).

Technology development and work processes improvement needs differ greatly in developing countries, and even in some cases between regions. For example, more so in Bangkok than many Northern areas. Building industrial capabilities requires technology exchange between local and international companies, government and research/education institutions. For instance, in order to deliver state-of-the-art manufacturing technologies, basic services such as electricity, water, raw material and work practices, are needed before sustainable industries can be put in place. MNCs contribute greatly in providing the foundation for technological development and industrial growth by providing examples to indigenous companies or subcontractors that might need to use state-of-the-art equipment or more efficient technology (Abdul-Gafaru, 2007). 
Building the Competence/skill of local workers has proved to be essential to the successful transfer and diffusion of technologies and knowledge. Whenever it is possible, MNC's prefer to hire local people rather than use expatriate employees. However, the lack of an adequately skilled workforce in the operating region presents a challenge to overcome. Low education levels of potential employees are a particular impediment to maximizing a local employee base. MNCs are often engaged in capacity building efforts and sometimes deliver education and training to groups in order to help them increase production levels and to perform work routines more efficiently (or communicate with other employees in the MNC). There is a recognized need to adjust approaches to education and training based on local conditions and local knowledge and skill levels. MNCs should see local universities as a good pool of competencies that will help ensure the sustainability of the transferred technology. Universities and R\&D institutions understand the local context and possess the knowledge that is valuable to MNCs. As well, they should be considered as the right partners for conducting joint research projects for technology maintenance or improvement, leading in some cases to new and innovative products or services (Worasinchai \& Bechina, 2010).

Increasingly, MNCs play key roles in global trade and investment, and in globally disseminating technology. MNCs are good in information-gathering, which allows them to be immediately aware of opportunities, problems and new developments, and they can draw on an enormous store of capital, technology,

and managerial skills. Obviously, the contributions of MNCs are 1) creating new assets by spotting the best production location; 2) generating international transfer of technology - "hard" or "soft"; and 3) making the most efficient allocation of the world's resources (Tayeb, 2005; Qi, 2007). Tayeb (2005) argued, the multinational nature of MNCs' workforces makes their human resource strategies, policies and practices perhaps one of the most delicate and complicated of all managerial tasks. The larger the MNC in terms of market and number of employees, the more complicated its business affairs and the more complex its management.

\section{Part II: Overview the Context of Thailand}

The history of Thailand dates back over 700 years and the Thai script was invented by King Ramkhamhaeng of the Sukhothai Kingdom in 1283 A.D. Since that time, Thai people have had both civilian and military governance systems. In effect, these systems were about human resource management and development. Today, while many Western HR concepts and practices are successfully implemented in organizations in Thailand, several concepts and practices are regarded as inappropriate and ineffective by Thai employees. Thailand owns its national conditions and culture, labor trends, labor laws, and HR issues (Roongrerngsuke 2005).

\section{Thai Social Context}

Buddhist beliefs and practices prevail in the Thailand. A central tenet of Buddhism is the belief in lifecycles, Vichit-Vadakan (2002 cited in Roongrerngsuke, 2005) said where all statuses, conditions or situations whether material or nonmaterial are but a temporary stage in an endless cycle of birth and rebirth before ultimate enlightenment can be attained. A fundamental part of elevating an individual's station in these cycles is the practice of giving, or the Thai Buddhist 
tradition of merit-making, which is usually done through philanthropy, charity, sponsoring, volunteering, or sharing. However, while generations are taught and socialized to be generous, charitable, caring and concerned about those who are in need, at the same time, many believe that doing good should be wholly pure and should not involve commercial interests. Charity is only good Karma if it is provided for the best of reasons, corporate philanthropy is often reciprocal and so not good Karma (Roongrerngsuke, 2005).

Therefore for Buddhists ethical behavior in business, economics and society more generally is the responsibility of individuals rather than of organizations taken in the abstract. So, in the same way that individual merit-making can turn into bargaining. Nonetheless, it was found that increasing numbers of businesses are embracing Buddhist principles and that acts of giving are lauded socially, especially when specific cases are made known through the media. There is no doubt Buddhist tradition is a strong factor encouraging socially responsible practices in the private sector in Thailand.

A second common cultural aspect that was brought up was the custom of non-confrontation, or conflict-avoidance. A common saying in Thailand regarding personal relationships is to keep the muddy water inside and clear water outside. There was general agreement that any sort of outward confrontation that results in bad feelings or a party losing face will damage or ruin a relationship. The negative implications of this on HR practices are that organizations will tend to screen out any potentially tense relationships with any community stakeholders and, even if a partnership is formed, problems can go unaddressed or unresolved and create dormant tensions that will worsen (Roongrerngsuke, 2005).
Another aspect that has had an effect on HR practices is the enormous amount of respect and devotion Thai people have for the monarch, His Majesty King Bhumibol Adulyadej. The King and the Royal projects and foundations that he has set up to advocate development causes and assist the poor have had a strong influence on the national development agenda.

A final major factor that was often discussed was the patronage system that still thrives in Thai society. As Vichit-Vadakan (2002 cited in Roongrerngsuke, 2005) notes, the patron client relationship [in Thai society] is a vertical affiliation where persons of unequal status enter into a formal or informal social relationship. This mutually beneficial form of relationship is the mechanism that links higher status persons to the many tiers of lower status persons in society. The patron client relationship is a principle of social organization in traditional Thai society, but it has also served to weaken and erode the horizontal linkages in society.

Therefore, it was found that hierarchical networking was absolutely necessary for success, especially within the development sector. It was pointed out and observed that powerful and respected individuals, usually former or current policymakers, were often sitting on the board of one or more of the more successful development agencies because they were more capable of mobilizing resources and connections with more tiers of clients. It was also stated that one of the main incentives and reasons why businesses schools were so competitive was because of the connections people make there, with one respondent stating that much of it is "about whom you meet, not what you learn" (representative from development sector). Therefore, it can be deduced that in a hierarchical society, the outlook for 
organizations interested in CSR practices will rely heavily on vertical networking and on the ability of their leaders to network horizontally at the upper classes of society. As Roongrerngsuke (2005) remarked, through the centuries, the foundation of Thai society, in the Thai conscious, is recognized as being based on three pillars:

the Nation (Chart), Religion (Sassana), and the Monarchy (Phra Mahakasat). Buddhism serves as a moral tone and social force of society.

\section{Thai Political context}

According to a newest report (Thai Board of Investment [BOI], 2011 b), Thailand will be a Green and Happiness Society in which people have integrity and knowledge of world standard; families are warm; communities are strong; society is peaceful; economy is efficient, stable, and equitable; environment is of high quality and natural resources are sustainable; administration follows good governance under the system of democracy with the king as head of state; and the country is a respected member of the world community. So that development under the Tenth Plan (2007-2011) pursues a Green and Happiness Society under the direction of the Sufficiency Economy philosophy.

However, the unemployment rate still remains high in comparison to pre-crisis levels. As Gross and Connor (2006 a) pointed out, Thailand has a labor force of 35 million people. There is an emerging middle class in Bangkok and other major cities, but a lack of skilled labor remains a serious human resource problem in Thailand. More than half of the national workforce is still employed in the agricultural sector. This sector, however, accounts for less than 10\% of GDP. Demand for skilled workers remains high. To tackle this problem, the government has instituted a "Reverse
Brain Drain Project", which seeks to attract Thai expatriates to return home and has had little success. In the first half of 2005 alone, 105,000 Thais left the country to find work overseas (Miller, 2006).

The lack of Thai nationals qualified for senior positions means that foreign and local companies must compete for the few candidates with experience and language skills. Those Thai who do fit the qualifications are garnering competitive salary and benefits packages, as companies in Thailand try to persuade them not to emigrate from Thailand to more modernized countries.

Most MNCs looking for skilled workers in Thailand may look to three sources for employees: indigenous Thai, foreign-educated Thai "returnees", and foreign expatriates. Among them, returnee candidates are often a better option. Although returnees demand better salaries and benefits, they also have a better education, experience in a Western business environment, and strong second language skills. Returnees are also often preferable to expatriate candidates. Unlike foreign expatriates, returnees also have an understanding of Thai business culture, language, and customs. Furthermore, the Thai government puts a number of restrictions on expatriate hiring. Foreigners working in the country must prove that no qualified Thai national is available for the job, and foreign employees are required to train a Thai co-worker to eventually replace them.

\section{Thai Labor laws}

Although still evolving, the Social Security Act passed in 1990 provides benefits to employees or family members of employees who have suffered from illness, disability, pregnancy, or death. Until enactment of this law, it was each 
individual company's prerogative to cover these circumstances. Now, firms with 10 or more workers are required to register with the Social Security Fund and the Department of Labor Protection and Social Welfare. The law grants support to Thai nationals in the private sector, excluding agricultural workers. Public employees are more comprehensively covered under a separate agreement that mandates health-related coverage for the employee, spouse and children, as well as the employee's parents (Gross \& Corner, 2006 b).

The Social Security Office has made it known that the increase will affect about four million workers. Their purchasing power is expected to increase by 14.69 billion baht as a result of this move (BOI, 2011 a). In the Social Welfare plan, all staff salaries are deducted 5\% (up to $750 \mathrm{baht} / \mathrm{month})$ for the purpose of social welfare. This then provides basic medical benefits for employees at selected hospitals (Blott, 2010).

In terms of working hours and leave, employees may not be asked to work longer than 48 hours per week, and 6 days per week, or less for jobs defined as dangerous. Working restrictions also exist for pregnant employees. A wide variety of leave days can be utilized by employees in Thailand, including up to 30 days per year for medical leave. If an employee takes 3 days or more consecutively for medical leave, the employer may ask to see a doctors certificate. Additionally, employees are permitted personal leave to handle government issues, and a minimum of 6 days per year annual leave once they have completed a year of employment. Other sources of leave are also permitted relating to monkhood, military service. Additionally, a minimum of 13 public holidays per year must be granted to employees, selected from the standard list (Blott, 2010).
In general, MNCs offer skilled employees wages $20-30 \%$ higher than those offered by Thai companies. Additionally, Western-educated Thai returnees in management positions can earn twice as much as locally educated managers. For example, a Pacific Bridge study showed that a Thai national with 11 years experience in the pharmaceutical sales industry is currently making approximately US\$29,000 at an international company in Bangkok. After studying in the United States, a Thai returnee with a similar background and only seven years of experience in Thailand is expecting US $\$ 48,000$ upon returning to Thailand.

The workweek for Thai nationals ranges from the typical 44 hours to 48 hours for a factory workweek and 54 hours per week for certain commercial employees. Retail employees work a maximum of nine hours per day, while those working with hazardous materials must stop after seven hours. Employers must permit a one-hour break for every five consecutive hours worked, and other breaks must be at least twenty minutes long by law. Workers cannot be forced to work overtime. If an employee chooses to work overtime, that individual may not work for more than four additional hours per day, and overtime may not occur for more than five consecutive days. Employers calculate overtime pay at 1.5 to 3 times the normal wage rate; MNCs must pay even more. Management officials are not subject to overtime pay unless stated in the employer-employee contract (Gross \& Corner, 2006 b).

\section{Part III: Review the Role of MNCs in Thailand} from the HR Perspective

The localization policy in many MNCs in local countries is being integrated into the company's business plan, so that corporations can respond quickly and easily to a teams' hiring 
requirements. These requirements vary widely, depending upon the company and the position being filled. In many cases, this policy is working well. Now most of the MNCs in Thailand are finding qualified local staff more easily, and try to fill all positions with local employees, even including the president or CEO of their Asia-Pacific operations (Liu \& Yu, 2007).

Usually the general characteristics MNCs look for in a local managerial candidate include fluent written and verbal English, a minimum of 5-7 years-experience in a particular field, a university degree, preferably an MBA, leadership and initiative abilities, creative problem-solving skills, and a professional attitude.

At present there are competent local candidates in managerial fields, including finance, engineering, human resources and sales, which can put location policy into practice more easily. However, there are still fewer qualified candidates than positions available, which make the sought after employees change their jobs frequently in order to gain the best benefits, financially and professionally. As a result, MNCs often suffer if their strategy is not one step ahead of the volatile recruitment market. For instance, companies hiring any local candidate should have retention tools and benefits policies beyond the minimum state-supported benefits. These may include incentive bonuses for reaching a specific target, training abroad, the cost of MBA schooling on a part-time or a full time, and as well career-path counseling. These strategies should be offered and monitored closely from the beginning. It is particularly important not to renege on promises made during hiring, not only for obvious ethical reasons but also because of gain and retaining local talents (Liu \& Yu, 2007).

\section{The Role of MNCs in Thailand}

Thailand has been one of the major FDI recipients in South-East Asia over the past two decades (McKinsey, 2002). In fact, in 2004, the United Nations Conference on Trade and Development (UNCTAD, 2005) sought to analyze "future patterns of FDI flows at global, regional, national, and industry levels", ranked Thailand as one of the four "top hot spots for FDI" in the world over the next four years, preceded only by China, India, and the United States. Thailand is ranked as the "Top 3" most attractive country for FDI flows in two separate categories: "Asia" and "Developing Economies". In Thailand, after 1997, the inflows of FDI continued to grow. Indeed, the growth of FDI by multinational firms in Thailand and elsewhere was so rapid in the late 1990s that it created the popular perception that multinational firms and their control of internationally integrated production activities are becoming more important in the world economy.

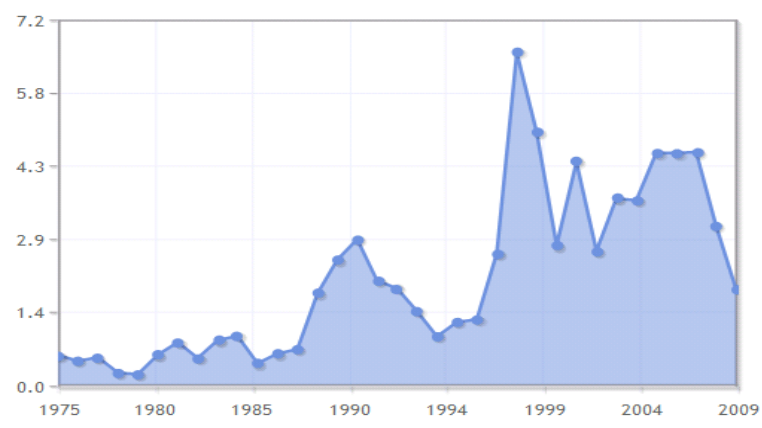

Figure 2 Foreign direct investment in Thailand, net inflows (\% GDP), from BOI's report (BOI, 2011 b)

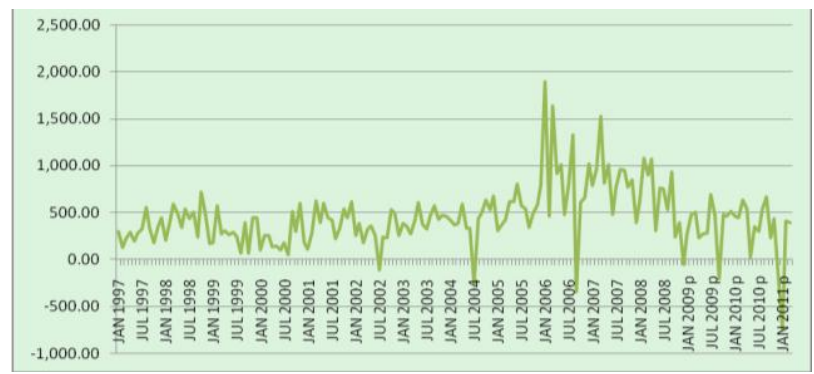


Figure 3 Total net flow of FDI in Thailand (Unit: Millions of US dollars) (BOI, 2011 b)

According to this two figures, as the share of FDI net inflows in GDP increases year after year, the contribution of MNCs to theThai economy is sustained growth. However, ratios of FDI to fixed investment and foreign capital flows are moderate in Thailand compared to other Southeast Asian economies. Singapore and Malaysia are two countries in that foreign MNCs literally dominate large sectors of these economies, accounting for a little over two-thirds of all manufacturing production in recent years in Singapore and about one-half of all manufacturing production in Malaysia, for example.

Besides, in Thailand as elsewhere, MNCs tend to dominate a few important sectors, the most prominent being electrical machinery and transport machinery manufacturing. These industries, including the foreign MNCs in these industries, have been a major source of growth in Thailand in recent years, especially in terms of exports. Furthermore, the fact that foreign MNCs dominate these industries is in many ways a technological accident. This is because investments in intangible, technology-related assets that are easily moved among production locations account for a relatively large portion of costs in these industries. As a result, firms in these industries face multi-plant scale economies, creating a motive for geographical dispersion, which is one of the most important characteristics of the MNCs.

HR Perspective toward the role of MNCs in Thailand

Although many MNCs in host countries have found local staff (as opposed to expatriate) they often still notice that local cultural, political, and procedural barriers are hard to surmount, and many MNCs in fact, do not clearly convey to local staff what actually needs to be done and why, discouraging local managers and employees from carrying out basic tasks and bettering their performance.

More Western MNCs in developing countries today try to get benefits from using human resource development (HRD) systems. In short, HRD takes the local employees beyond compliance and can be used to enhance and build a quality program. This is particularly important in developing countries, where education systems and management notions have historically been exemplary at meeting (and only meeting) requirements in order to put people to work.

HRD provides skills training to enrich the local employee's current experience and increase his or her overall competence, and help local employees to analyze the gap between "what is" and "what should be" in their work, which helps to highlight the importance of satisfying customer needs.

In conclusion, in Thailand, the following HR issues are most important:

1) Human resources are critical to sustaining growth in Thailand's rapidly advancing economy. Raising the skill levels of Thailand's labor force -- particularly in the fields of science and engineering -- will be a key factor for Thailand's modernization.

2) Thai culture focuses on respect. Thais acknowledge paternalistic hierarchy and are typically hesitant to challenge those in a position of authority. Rather, they feel most comfortable when others are patient and willing to compromise. Thais value the "team" and are generally loyal to those who treat them fairly (Gross \& Connor, 2006 a).

3) The recent surge of business investment, 
coupled with the lack of skilled workers, creates a highly competitive market for employees. As BOI (2011 a) points, companies strive to provide both a satisfactory salary plan and a comfortable work environment in order to maintain satisfied employees, and thus discourage the prevalent trend of job-hopping.

4) Thailand is seeking to improve its general level of education and is encouraging universities to target key areas of need -science and engineering -- by offering relevant courses and degrees. Companies have encouraged the development of science programs by offering scholarships and developing in-house training.

5) Thai labor laws are designed to protect workers and preserve their rights. These laws dictate the minimum standards for salary and benefits and the maximum amount of work hours and days. The labor law provides a reasonable work environment and protects against labor exploitation (Blott, 2010).

6) Minimum wage laws are structured to encourage investment outside the metropolitan area of Bangkok. The Thai government allows businesses to utilize inexpensive labor in other provinces in an effort to abate traffic, pollution, and infrastructure bottlenecks in the urban areas.

7) Health care coverage is a main concern for many Thais. The Thai government recently made great improvements to its labor laws, granting better benefit plans and reducing the financial burden on the employee in case of illness or accident (Gross \& Connor, 2006 a).

8) Termination procedures have been developed to protect both the employer and employee. Regulations are fair, requiring notification of termination as well as severance pay for an otherwise loyal employee. Although qualified employees are permitted recourse against unjustified termination, the company has no obligation to a negligent or malevolent worker.

As Roongrerngsuke (2005) mentioned, Thai values are different from Western country values. Sometimes, some Thai values such as the Kreng-jai, seniority system, patron-client system, nepotism, Katanyu Katawethi, face-saving, and conflict avoidence can sometimes be misunderstood, misinterpreted and inappropriately practiced in organizations, resulting in unfair and unethical management of human resources. Table 2-12 summarizes Thai values in comparison with values underlying performance management.

Table 3. Thai value and performance management: problems or prospects

(Roongrerngsuke, 2005, p. 165)

\begin{tabular}{ll}
\hline \multicolumn{1}{c}{ Thai Values } & \multicolumn{1}{c}{$\begin{array}{c}\text { Performance Management } \\
\text { Values }\end{array}$} \\
\hline - Sanuk: fun-loving & - Transparency \\
- Sabai Sabai: & - Fairness \\
care-free, easy-going & - Equality \\
- Kreng jai & - Performance \\
- Seniority system & - Open-communication \\
- Patron-client system & - Trust \\
- Favoritism (nepotism) & - Loyalty \\
- Kantanyu Katawethi: & - Teamwork \\
reciprocating favors & \\
- Face-saving & \\
- Conflict avoiding & \\
\hline
\end{tabular}

Roongrerngsuke (2005) pointed out many traditional values are very worthy and valuable and 
should be retained in society in the workplace, as they help create good relationships, trust, team-spirit and harmony among works, especially during times of economic difficultly.

\section{Conclusion}

The localization policy in many MNCs in local countries is being integrated into the company's business plan, so that corporations can respond quickly and easily to a teams' hiring requirements. It is important to develop the correct understanding and practice of those values among employees. Unfair treatment in the workplace are usually caused by inept leader. HR, alone, cannot create a high-performing culture in an organization, without support from top management. Top management, therefore, must be a good role model in preserving traditional values, while reinforcing fairness, ethics and transparency in the organization- otherwise, a truly, high-performing, work environment can never be established in Thailand. To be successful abroad, MNCs need understand the local culture and customs. Additionally, HR executives must understand the legal framework and the workplace issues that are most important to the local people.

\section{References}

Abdul-Gafaru, A. (2007). Are multinational corporations compatible with sustainable development in developing countries? Retrieved Apirl 29, 2011, from http://ciber.gatech.edu/papers/workingpaper/20 07/001-07-08.pdf

Blott, S. (2010). Labour law in Thailand. Retrieved August 7, 2011, from http://thailand-hr.blogspot.com/2010/08/labourlaw-in-thailand.html
Fatima, S. (2007). MNCs and globalization: Overview of the role of MNCs in global business. Retrieved July 22, 2011, from http://www.suite101.com/content/ mncs-and-globalization-a21062

Gross, A., \& Connor, A. (2006 a). Thailand HR update. Retrieved June 19, 2010, from http://www.pacificbridge.com/publications/thail and-hr-update-2006/ (2006 b). Thailand human resource. Retrieved September 2, 2011, from http://www.pacificbridge.com/areapublication.a $\mathrm{sp}$ ?

Johnson, D., \& Turner, C. (2003). International business: Theory \& practice. London: Routledge.

Liu, D., \& Yu, J. N. (2007). Human resource strategies in multinational corporations in China. Master's thesis, Economics and Management School, Wuhan University.

McKinsey Global Institute. (2002). McKinsey report: Thailand: Prosperity through productivity. Bangkok: McKinsey Global Institute.

Miller, D. (2006). The migration dialogue. Berkeley: University of California.

Roongrerngsuke, S. (2005). Best HR practices in Thailand. Bangkok: Nation News Network.

Tayeb, M. H. (2005). International human resource management: A multinational company perspective. NY: Oxford University Press.

Thai Board of Investment [BOI]. (2011 a). Thailand minimum wages 2011 increase. Retrieved March 11, 2011, from http://www.business-in-asia.com/thailand/ minimum_wage2011.html

Thai Board of Investment [BOI]. (2011 b). Why Thailand. Retrieved May 10, 2011, from 
http://www.boi.go.th/ index.php?page=index

The United Nations Conference on Trade and Development [UNCTAD]. (2005). World investment report: Transnational corporations and export competitiveness. Retrieved March 1, 2011 , from http://archive.unctad.org/Templates/Page. asp?intItemID $=5162 \&$ lang $=1$

Worasinchai, L., \& Bechina, A. A. (2010). The role of multinational corporations (MNCs) in developing R\&D in Thailand: The knowledge flow Between MNC and university. Knowledge Management, 8(1), 171-180. 